\title{
La cultura catalana a Itàlia: el cas de Cesare Giardini
}

\author{
Patrizio Rigobon \\ Università Ca' Foscari Venezia \\ Dipartimento di Studi Linguistici e Culturali Comparati \\ Dorsoduro 3246 \\ 30123 Venezia \\ rigobon@unive.it
}

Resum: L'article estudia alguns aspectes de la vida i de l'obra del catalanòfil italià Cesare Giardini (Bolonya, I893 - Milà, 1970) fins a la dècada dels anys trenta del segle Xx. La seva activitat inicial d'actor li va permetre viatjar a Barcelona el I9I2 amb la companyia de la gran actriu italiana Lyda Borelli. Es va quedar a Barcelona durant un mes i, arran d'aquesta visita, va poder contactar amb alguns representants de la cultura catalana, tot $\mathrm{i}$ que encara era molt jove. A partir dels anys vint començà a treballar a l'editorial Alpes de Milà, que va publicar traduccions d'obres catalanes a l'italià, com ara La nazionalità catalana, d'Enric Prat de la Riba (I924). La seva tasca de difusió de la literatura catalana es va desenvolupar també mitjançant moltíssims articles a diferents diaris i revistes durant tota la seva trajectòria vital. Va publicar l'any 1926, amb l'editorial de Piero Gobetti (Edizioni del Baretti), una antologia de poetes catalans, que va reeditar amb pocs canvis l'any 1950.

Paraules Clau: Giardini, Estelrich, Prat de la Riba, catalanisme, feixisme

\section{Catalan Culture in Italy: the Case of Cesare Giardini}

Авsтract: This paper looks at aspects of the life and work of the Italian Catalanophile Cesare Giardini (Bologna I893-Milan 1970) up until the I930s. Giardini's initial activity as an actor afforded him the chance to travel to Barcelona in I9I2 with the theatre company of the great Italian 
actress Lyda Borelli. During the month that Giardini spent in Barcelona, he was able to get in touch with a number of representatives of Catalan culture despite his considerable youth. In the I920s, he began working with the Milan publishing firm Edizioni Alpi, which published Italian translations of Catalan works, such as The Catalan Nationality by Enric Prat de la Riba (1924). Giardini's efforts to disseminate Catalan literature also involved his publication of a large number of articles in various newspapers and magazines throughout his long career. In 1926, he put out an anthology of Catalan poets through the publishing firm of Piero Gobetti (Edizioni del Baretti) and this anthology would be reprinted in 1950 with few changes.

Keywords: Giardini, Estelrich, Prat de la Riba, Catalanism, fascism

Abans que res voldria mostrar el meu agraïment als organitzadors d'aquesta jornada que ret homenatge a un mestre de la història cultural, el doctor Jordi Casassas, figura central d'aquests estudis a Catalunya i arreu. Les obres del doctor Casassas constitueixen una fita de la meva formació i m’han obert el camí, que sempre havia buscat, entre la filologia, les estructures socials i polítiques i l'histoire événementielle; entre les idees que determinen l'acció política i l'elaboració teòrica. És un camp d'estudis que té una tradició ben llarga i que, en el cas de Catalunya, es relaciona íntimament amb, com diria Burke, «the making of a nation» i tot allò que hi ha darrere d'aquest concepte, com ara les institucions culturals i les idees. Quan vaig llegir les obres de Jordi Casassas, vaig considerar aquesta opció, que, en termes generals, m'interessava $\mathrm{i}$ ja estava marcada dins els estudis d'història contemporània catalana pels treballs del doctor Casassas. Per tot això, doncs, moltíssimes gràcies!

Fa més de deu anys vaig ser convidat a l'Ateneu per parlar sobre la traducció italiana de La nacionalitat catalana, invitat per l'homenatjat. Era un tema que havia tractat, molt parcialment, en la meva 
tesi doctoral i que havia tornat a estudiar alguns anys després. Quan vaig començar aquest estudi, faltaven documents imprescindibles per analitzar la qüestió: les cartes que Cesare Giardini, traductor i catalanista, va intercanviar arran dels seus projectes editorials i de l'activitat de divulgador. Ara moltíssimes d'aquestes cartes ja estan a la disposició dels estudiosos i jo les estic fent servir per a un llibre que estic escrivint sobre aquest quasi desconegut $\mathrm{i}$ infravalorat, encara avui, personatge italià. Les fonts d'aquesta xerrada meva són, doncs, majoritàriament inèdites i formen part dels arxius personals de molts catalans que van estar en relació epistolar amb Cesare Giardini i que s'han llegat a institucions públiques: els fons Joan Estelrich, Tomàs Garcés i Jaume Bofill i Mates de la Biblioteca de Catalunya; el fons Carles Riba de l'Arxiu Nacional de Catalunya; el fons López i Picó de l'Arxiu Històric de la Ciutat de Barcelona; el fons Ramon d'AlòsMoner de l'Institut d'Estudis Catalans; el fons Joan Arús de l'arxiu particular d'Isabel Mach del Centre d'Estudis de Castellar del Vallès, i la correspondència de Prudenci Bertrana del fons Bertrana de la Universitat de Girona. A banda d'això, s'ha de dir també que un epistolari fonamental, perquè documenta una relació importantíssima, ja no el tenim: es tracta de les cartes entre Giardini i Alfons Maseras. Sabem, per altres epistolaris, que havien intercanviat moltes lletres, però malauradament s'han perdut. N'esmento només un d'aquests epistolaris perduts, perquè la llista podria ser més llarga: un problema força freqüent també al segle xx. ${ }^{\mathrm{I}}$ Per sort, ens queden

I En general, el futur de les cartes (rebudes i enviades) depén, sobretot al segle xx, també dels hereus, perquè, com subratllava Mario Richter, «I primi controllori e mediatori delle lettere sono qualche volta o gli stessi corrispondenti o, più frequentemente, gli eredi diretti" (dins Elio D’Auria, Metodologia ecdotica dei carteggi. Atti del Convegno Internazionale di Studi. Roma 23, 24, 25 ottobre 1980, Florència, Le Monnier, 1989, pp. 259260). El cas de Giardini, però, també en aquest sentit és especial, perqué no hi ha hereus coneguts (Giardini no tenia fills) i les cartes es perden definitivament també per aquesta raó. 
cartes de Giardini a nombrosos personatges, molts de gran relleu dins la història cultural del segle xx italià i europeu. Potser Giardini és allò que es diu un «menor» entre els "grans», però, com bé matisa Narciso Nada, «il confine tra queste due categorie è sempre assai labile e sfumato. Del resto un determinato personaggio può magari essere considerato di secondaria importanza sotto certi aspetti, mentre può avere una posizione di rilievo sotto certi altri». ${ }^{2} \mathrm{I}$, dins el petit món de les editorials italianes, Giardini hi tenia un paper de relleu i les cartes en són una prova. Tenim avui dia molts epistolaris entre «editors» $\mathrm{i}$ «autors» que demostren «ignote e fertili interazioni tra la (grande) Storia e le (piccole) storie» tot revelant així «un percorso promettente, ricco di sorprese e spunti all'incrocio fra interessi e discipline». ${ }^{3} \mathrm{El}$ paper de Giardini va ser moltes vegades «doble»: «sobretot editor» durant una primera etapa, i «sobretot autor» durant una segona etapa (a partir de la dècada dels trenta), però sempre traductor. Molt sovint les funcions es van solapar.

Pel que fa a la cultura catalana, hem de considerar que Giardini va conèixer personalment potser només un o dos dels seus corresponsals catalans (Ramon d'Alòs-Moner i August Matons, que el varen veure a Milà). Amb tots els altres, les comunicacions es feien amb cartes i és segur que moltes s'han perdut (o no estan disponibles) per una raó força concreta. Sobretot s'han perdut (i definitivament) les cartes rebudes dels seus corresponsals catalans fins l'any I943. Dels bombardeigs de Milà de l'any i943 en parla sovint a les seves lletres: "sono stato a Milano a vedere la mia casa distrutta: ho perduto 3000 volumi e mobili e robe... Milano è ormai inabitabile né so quando ci si potrà tornare: ti assicuro che quando l'ho vista ridotta a uno scheletro polverso e fumoso, mi si è stretto il

2 Ibidem, p. 83.

3 Maria Pia Casalena, "Le lettere come documenti e come testi», Contemporanea, vol. 9, núm. I, 2006, p. 205.

Cercles. Revista d'História Cultural, 22 (2019), 111-134. ISSN: 1139-0158. ISSN-e: 1699-7468. DOI: 10.1344/cercles2019.22.1004. 
cuore». ${ }^{4}$ I, set anys més tard, tot escrivint a Joan Estelrich sobre l'Antologia di poeti catalani contemporanei:

Saprà che la nostra vecchia Antologia di poeti catalani contemporanei, un po' aggiornata (ma molto poco, perché non avevo i testi o, meglio, li ho avuti troppo tardi) è riapparsa nelle edizioni Garzanti. Avrei voluto (ed era anche desiderio dei direttori della collezione in cui il libretto figura) aggiungere alla parte moderna, una parte riguardante il primo rinascimento catalano, ma il materiale bibliografico che mi sarebbe servito era andato distrutto nel bombardamento della mia casa in un mucchio di tremila volumi, tra cui erano quelli bellissimi della «Fundaciò Bernat Metge».5

Tot i així, tenim suficient material per esbossar una semblança de Cesare Giardini i de la seva molt intensa i llarga activitat de catalanòfil i catalanista a Itàlia (ho diem també en un sentit polític), gràcies també als documents que es conserven als arxius històrics de les editorials italianes més importants, que van tenir Giardini com a apreciat collaborador. Em refereixo sobretot als documents que es poden localitzar a la Fondazione Arnoldo e Alberto Mondadori, al Fondo Bompiani de l'Archivio Rizzoli, a l'arxiu de l'Istituto per gli Studi di Politica Internazionale de Milà i també al Fondo Gobetti de l'arxiu del Centro Studi Piero Gobetti de Torí. He trobat altra correspondència més o menys dispersa a Roma (Fondo Ciarlantini,

4 Giardini a Bompiani, 24 d'agost de I943. Fondo Casa Editrice Valentino Bompiani (Milà). Archivio Rizzoli. Area Editoriale. Serie "Corrispondenza con gli autori». Segnatura $\mathrm{I} 42 \mathrm{ACEB}$.

5 Giardini a Estelrich, 25 de novembre de 1950. Fons Joan Estelrich. Arxiu Biblioteca de Catalunya. Dec la consulta d'aquestes cartes, en procés de catalogació, a la amabilitat i disponibilitat de Manuel Jorba i Anna Gudayol. V. també Manuel JorbA, «Un arxiu per a unes memòries: el fons Joan Estelrich de la Biblioteca de Catalunya", dins Actes de les Jornades d'Estudi sobre Joan Estelrich. Palma-Felanitx I7, I8 i 24 d'octubre de 2008, Barcelona, Publicacions de l'Abadia de Montserrat / Consell Insular de Mallorca, 20 Io. 
Fondo Pettinato i Fondo Pellizzi de la Fondazione Ugo Spirito e Renzo De Felice) i Florència (al Fondo Giuliotti de l'Archivio Contemporaneo Alessandro Bonsanti del Gabinetto G.P. Vieusseux). Altres documents els he localitzat a Lugano, Venècia, Vicenza, Oftringen, Urbino, París, Gènova, Roma i Pavia. També l'obra de Giardini està essencialment dispersa a - literalment - desenes de diaris i revistes, alguns dels quals citarem, i no sempre l'autor ha recollit els seus articles en llibres. Per entendre la importància de la figura de Cesare Giardini per al coneixement de la cultura catalana a Itàlia, cal subratllar també que no es tracta d'una passió de relativament pocs anys (com és el cas del seu amic Giuseppe Ravegnani), sinó d'una preocupació que va durar fins a la fase final de la seva vida (I960-I970). Nosaltres ens centrarem sobretot en la primera i més prolífica etapa: els anys vint del segle passat. I, dins d'aquesta etapa, tractarem només d'alguns aspectes, perquè hi ha també, en aquest sentit, un excellent article de Giovanni C. Cattini, ${ }^{6}$ a banda d'altres intervencions puntuals sobre el tema.

Com, quan i per què neixen el catalanisme i la catalanofilia de Giardini? Intentarem contestar aquestes preguntes que mai (o molt poc) s'han tractat i que són especialment importants a l'hora d'establir connexions amb l'àmbit europeu, connexions sempre fonamentals per als intel.lectuals catalans. Cesare Giardini, que havia nascut a Bolonya el I7 de febrer de 1893 , era fill i nebot d'actors. Ell mateix ens ho explica en un llibre, no gaire conegut, que es diu Ricordi di teatro. Frammenti d'una autobiografia, preceduti da un sonetto. ${ }^{7}$ Es tracta d'una edició per a bibliòfils que es pot llegir a molt poques biblioteques. Comença així:

6 Giovanni C. Cattini «Joan Estelrich i l'Expansió Catalana. La traducció de Prat de la Riba i Cambó en la Itàlia feixista», Cercles. Revista d'Història Cultural, núm. I2, gener 2009, pp. 75-89.

7 Milà, Architipografia di Milano, I930.

Cercles. Revista d'História Cultural, 22 (2019), 111-134.

ISSN: 1139-0158. ISSN-e: 1699-7468. DOI: 10.1344/cercles2019.22.1004. 
Dai quattro ai dieci anni [...] ho creduto che il teatro fosse una cosa seria. Venne poi un'epoca nella quale del teatro non m'occupai e una terza, dopo la guerra, in cui giudicai il teatro necessario. Fu quando facendo l'attore mi guadagnavo la vita. Oggi [I930 nda], che non recito più, il teatro mi pare inutile [...] Dell'avere io preso per un certo periodo di tempo sul serio il teatro, sono responsabili i miei parenti che erano e sono tutti attori e figli e nipoti d'attori. ${ }^{8}$

El llibre té molts trets autobiogràfics, però també pretén parlar d'una època i dels actors. Una de les característiques dels «vecchi comici» és "quella di aver viaggiato quanto Odisseo e Magellano e di non aver veduto nulla». ${ }^{9}$ També hi ha referències a les activitats del Giardini postteatral. Escriu Giardini tot parlant d'un actor que coneixia: «egli non era - per usare la definizione di un mio amico catalano - un temperamento da dialogo che è quanto dire un temperamento scientifico, sibbene un temperamento da monologo e cioè un temperamento dogmatico». ${ }^{\text {IO }}$ No sabem el nom d'aquest amic català: els anys 1929 i 1930 Giardini tenia molts amics i coneguts a Catalunya. En aquest sentit, sobta que no evoqui la que va ser possiblement la seva única estada a Catalunya, l'any I9I2. D'això en tenim constància a l'epistolari en dues cartes, però no en dona gaires detalls. Aquests els afegirem nosaltres amb la investigació que hem pogut fer. Escriu a la primera carta, en italià — com quasi sempre escrivia als seus corresponsals catalans_-, dirigida a Joan Estelrich el i7 de novembre de I922; la segona, en francès, a Josep Maria López-Picó un mes abans, el i6 d'octubre de I922):

8 Ibidem, p. I7.

9 Ibidem, pp. 25-26.

Io Ibidem, p. 35 .

Cercles. Revista d'Història Cultural, 22 (2019), 111-134. ISSN: 1139-0158. ISSN-e: 1699-7468. DOI: 10.1344/cercles2019.22.1004. 
Certo, le invierò quanto andrò scrivendo sulla sua bella patria alla quale mi riconduce talvolta un ricordo nostalgico per quel cielo di cui dice en López-Picó: 'la clara / infinita blavor del nostre cel / amarà / la nostra vi(d)a com el pa la mel/ e per quelle strade grandissime: così grandi che il cielo sembra discendere a riempirle d'azzurro. Io fui a Barcellona nel I9I2 - avevo diciott'anni [realment en tenia dinou, n.d.a] - e non l'ho più dimenticata. Abitavo in 'Plaza del Buensucceso' a lato del 'Paseo de Gracia', credo de 'la Rambla de las flores'. Spero di ritornare in un giorno futuro per conoscere di persona i valorosi letterati che mi sono venuti incontro con tanta fraternità. ${ }^{\text {II }}$

Va ser molt més concís Giardini a la carta, en francès, a Josep Maria López-Picó d'un mes abans, el I6 d'octubre de I922: "Je dèsire seulement de nouer avec votre beau pays - dont j'ai un souvenir lointain mais toujours prèsente de lumière et de beauté - des liens d'intellectualité fraternelle et de fraternelle amitié toujours plus etraits». ${ }^{\mathrm{I}}$ Malgrat que, en el record, la topografia quedi una mica alterada, a l'epistolari hi ha múltiples referències a Barcelona, sempre amb un desig de tornar-hi que, però, a la darrera carta a Estelrich de I950, Giardini sembla ja no poder satisfer: «Barcellona rimane per me il paese nel quale desidero ritornare più che in qualunque altro, con ben poche speranze di realizzare questo sogno». ${ }^{\mathrm{I3}}$ Què hi feia, a Barcelona, Giardini l'any I9ı2? És ben senzill: Giardini era actor, i juntament amb el seu pare, Vittorio, formava part de la Drammatica Compagnia Italiana Gandusio-Borelli-Piperno, que, procedent de Madrid, va actuar a Barcelona durant el mes de maig de I9I2. La

II Fons Joan Estelrich. Arxiu de la Biblioteca de Catalunya.

I2 Epistolari «G». Fons AHCB3-299/5D46 Josep M. López i Picó. Arxiu Històric de la Ciutat de Barcelona.

I3 Carta a Joan Estelrich, 25 de novembre de 1950. Fons Joan Estelrich. Arxiu de la Biblioteca Nacional de Catalunya. 
gran actriu italiana Lyda Borelli hi va tenir un èxit extraordinari, segons la premsa de l'època. Subratllem només un fet casual, o potser no tant. Alexandre Plana va escriure una ressenya sobre l'actuació de Lyda Borelli a Barcelona i podria haver conegut als actors en aquella circumstància. Ho dic perquè Alexandre Plana, crític teatral, és el mateix autor d'una antologia de poesia catalana que Giardini cita molt sovint a les seves cartes. Casualitat? Potser. Giardini tornarà a esmentar el seu pas per Barcelona dotze anys després. I, en aquest cas, ens assabentem que durant la estada de I9I2 Giardini ja tenia interessos literaris. Tot commemorant Àngel Guimerà en un diari italià, va escriure l'any 1924: "In un giorno lontano quando fui a Barcellona, un amico mi additò la sua [de Guimerà] casa, in fondo alla Piazza del Pino, ben lontana dalle vie rumorose della città cosmopolita, lontana dalla Rambla, dalla Plaça de Catalunya, dal Paseig [sic] de Gràcia, dalle vie in cui turbinosa si svolge la vita della capitale marinara e industriale, intellettuale e gaudente». ${ }^{14}$ Fer d'actor en una companyia on treballava una jove, però ja molt coneguda, actriu significà contactesa la ciutat, i apropament a la seva vida cultural. Cal no oblidar tampoc que el I9I2 és també un any de debats, diguem-ne, autonòmics i de gran activitat política d'Enric Prat de la Riba a la Diputació barcelonina. Tal com escriuria deu anys més tard Giardini: «In un tempo relativamente breve gli intellettuali catalani hanno portato la loro patria, che giaceva nell'ignavia e nell'incoscienza più assolute, al livello delle altre nazioni europee. È logico che queste guardino con simpatia al prodigioso rifiorire degli studi e della poesia in Catalogna». ${ }^{15}$ L'estada barcelonina de Giardini s'acabà a finals de maig de I9I2 i, malgrat que les localitats del Teatre Novetats no sempre s'esgotessin, l'èxit de Lyda Borelli i la seva companya va ser rodó. Segons Alexandre Plana:

I4 Il Resto del Carlino, 22 d'agost de 1924.

I5 Il Secolo XX, I de maig de i922, p. 404.

Cercles. Revista d'Història Cultural, 22 (2019), 111-134. ISSN: 1139-0158. ISSN-e: 1699-7468. DOI: 10.1344/cercles2019.22.1004. 
la nit del divendres [3I de maig], quan la companyia italiana prenia comiat del nostre públic, era de veure com al caure de la cortina sobre la darrera escena de La donna nuda, ningú mostrà aquella pressa per a deixar el teatre que sol tenir fins en les nits de comiat. Tothom assegut en la butaca, ó de peu dret, aplaudía als actors sense la cara inexpressiva que's fá quan se pica de mans per compromís; en cada boca hi havia un somriure, y cada aplaudiment sonava a recansa. La Lyda Borelli, amb la seva figura ágil y deliciosa, se movia entre'ls seus companyons d'escena y [...] agrahía la perllongada y sinceríssima ovació. ${ }^{16}$

La revista El Teatre Català fins i tot va dedicar a l'actriu italiana la primera plana de l'edició de maig de I9I2. El mateix mes de maig de I9I2, al Teatre Principal també estava actuant Margarida Xirgu. Cesare Giardini s'havia quedat, doncs, un mes a Barcelona, i també s'havia quedat un mes a Madrid, però ja no tornaria amb Lyda Borelli quan l'actriu italiana, fent una escala a Barcelona procedent d'Amèrica, va actuar a la capital catalana, només per deu funcions, el mes de novembre de 19I4. ${ }^{\mathrm{I}}$ No consta a cap lloc que Cesare Giardini estigués a la companyia de l'actriu italiana durant la segona gira barcelonina. ${ }^{\mathrm{I}}$ La Gran Guerra va esclatar i Cesare Giardini, com milions d'italians i europeus, va ser allistat a l'exèrcit. És probable que en aquells anys

i6 El Poble Català, 3 de juny de I9ı2, p. 3.

17 Segons Loreto Busquets, «E a dir poco curioso che [a Barcelona] la compagnia della Borrelli abbia destato un così scarso interesse da non suscitare né i commenti della stampa né quelli da uomini di teatro o intellettuali in genere» (Lidia Bonzi i Loreto BusQUETS, Compagnie teatrali italiane in Spagna, I885-1913, Roma, Bulzoni, 1995, p. 620). Aquesta asseveració s' hauria potser de revisar contrastant-la millor amb els articles de diaris i revistes. El mateix Plana havia escrit a El Poble Català (3 de juny de 1912, p. 3): «Ha estat un triomf rapidíssim i memorable, el de la Lyda Borelli sobre el públic barceloní». I el I9I4 van fer amb l'actriu dues entrevistes (El Teatre Català, I4 de novembre de 1914, pp. 744747, i El Poble Català, is de novembre de 1914, p. 2).

i8 V. Maria Ida Biggi, Marianna Zannoni i Maria Dolores Cassano, Il teatro di Lyda Borelli, Florència, Fratelli Alinari, 20I7, p. $2 \mathrm{II}$. 
Giardini conegués un altre catalanòfil i catalanista italià, Giuseppe Ravegnani (que, juntament amb Alfredo Giannini, forma part del grup dels fundadors de la moderna catalanística italiana): tenim una carta de Giardini a Ravegnani del 9 de juliol de $1917^{\text {I9 }}$ que demostra una relació encetada temps enrere. Em pregunto: per qué — malgrat que sempre hagi estat un tema d'intel.lectuals, o sigui d'escriptors, i, per tant, una mica elitista- hi ha hagut una atenció tan gran i profunda als temes catalans per part d'aquests italians? Hi ha moltes raons, naturalment, però no em sembla gens marginal l'associació entre literatura i política. Amb aquesta connexió, s'ofereixen al «poble» novel.les, poemes, teatre, etc., que poden apropar els escriptors al mateix poble, amb vista a una política nacional. Escriu Giardini: «Non è facile assodare se in Catalogna sia stata la rinascita poetica a dare impulso al risveglio politico, o viceversa. Bisognerebbe forse dire che vi furono due correnti d'influenza naturale sfocianti ad una stessa meta». ${ }^{20}$ I la simpatia política envers Catalunya es consolidarà encara més tot just a la segona meitat dels anys vint del segle XX. El I928, l'editorial Carabba de Lanciano (que ja havia editat moltes traduccions de literatura catalana) publica La fiera di Montmartre, d'Alfons Maseras, i els traductors (Brinzi i Lo Presti) anoten a la introducció:

Alcuni avvenimenti di natura politica han richiamato, recentemente, l'attenzione degli intellettuali dei due mondi sui separatisti, che, rifugiati in Francia, perseguono con generosa fede e sorprendente tenacia l'intento di redimere la patria catalana dal giogo dello Spagnolo.

La quistione posta nuovamente in primo piano non è del tutto nota, alla gran massa dei lettori, nella sua origine e nei suoi particolari [però] questi brevi cenni [...] dovrebbero maggiormente riguardare l'opera di Maseras: opera ispirata all'amore profondo per la sua terra

I9 Fons Ravegnani. Biblioteca Bonetta (Pavia).

20 Il Secolo XX, I de maig de I922, p. 397.

Cercles. Revista d'Historia Cultural, 22 (2019), 111-134. ISSN: 1139-0158. ISSN-e: 1699-7468. DOI: 10.1344/cercles2019.22.1004. 
e al retaggio di libertà, indipendenza ed inquietudine che l'anima catalana conserva intatto e ad essa lasciato da quei navigatori che, pari a quelli di Genova e Venezia, corsero, un tempo, il sacro mare nostrum. ${ }^{21}$

La sorprenent actualitat d'aquesta introducció no ens ha de desviar del camí d'interpretar una situació evidentment diferent. La construcció de la imatge internacional de Catalunya, de la Catalunya de la segona i tercera dècades del segle xx, depenia aleshores de la seva literatura molt més que avui, i Cesare Giardini, encara actor al començament dels anys vint, començà la seva activitat de difusor i paladí de la cultura catalana a Itàlia. Ho feu després de Giuseppe Ravegnani, però amb més continuïtat, i molt després d'Alfredo Giannini, però amb una dedicació a la cultura catalana potser més absorbent. Hi havia grans diferències entre tots tres, que - repeteixo- es coneixien molt bé i fins i tot van collaborar (Giardini i Ravegnani) en la tasca de difusió de la cultura catalana a Itàlia. Giannini parlava un excel.lent català. I es nota al seu epistolari, en què fa servir quasi sempre el català com a llengua de comunicació (en comptes de l'italià emprat per Ravegnani i Giardini quan escrivien als seus amics catalans). Giannini i Ravegnani tenien una formació universitària, i Giannini va ser el primer professor de català a una universitat italiana, concretament a Nàpols, on va encetar aquesta assignatura l'any I92I. Tal com el mateix Giannini ho explica a Joan Estelrich en una postal del 9 de setembre de 1920: «En la meva carta us deia que pel nou any seré oficialment [subratllat de l'autor] ensenya[n]t de català (amb el castellà) a l'Universitat de Nàpols, com que la Facultat m'encarregat d'això. No n'esteu de content?». ${ }^{22}$

2I Alfons Maseras, La fiera di Montmartre, traducció, introducció i notes de V. Brinzi i S. Lo Presti, Lanciano, Carabba, I928, p. 5.

22 Postal de Giannini a Estelrich, 9 de setembre de 1920 . Fons Joan Estelrich. Arxiu de la Biblioteca de Catalunya. 
Giardini era un irregular. Fins i tot desconeixem els seus estudis. Segons algunes fonts. no hauria estudiat més que l'equivalent italià del cinquè any de l'educació primària. Tenim el testimoni de Silvana Mauri, neboda de l'editor Valentino Bompiani i secretària de direcció a l'editorial, que havia entrat en amistat amb Cesare Giardini. Al seu dietari ( 8 de març de 1945) en fa aquest retrat:

È venuto [a l'editorial] Giardini [...]. Era molto triste. Ha detto che zio Valentino è un editore speciale, difficile nei gusti e questo è più che giusto. In vena di confidenze, mentre aspettavamo che zio sciogliesse di là la seduta, mi ha raccontato che è figlio d'attori, attore da giovane lui pure, e autodidatta. È stato a scuola fino alla quinta elementare. Poteva essere patetico, se non fosse stato cos̀ forte della sua superiorità sui 'regolari', così certo della sua cultura, mentre accusava il complesso d'inferiorità di fronte ai diplomati. Giardini si è rattristato da che lo conosco, si veste di scuro ora che viene primavera, e giunge sempre con la valigia sulla porta. Quest'inverno vestiva splendidamente di chiaro e si sedeva soddisfatto a fumare. ${ }^{23}$

No hem trobat, com dèiem, cap document sobre els estudis de Giardini, a banda d'aquesta al.lusió. Li faltava potser la dimensió problemàtica i filològica de la història i del text literari, però, com a gran i voraç lector que era, va omplir, tal vegada desordenadament, els buits en la seva formació, si és que, com diu la font, va estudiar només els cinc anys de les scuole elementari. Giardini comença escrivint ressenyes d'obres literàries, teatre i crítica artística, sobretot de

23 Silvana Mauri, Ritratto di una scrittrice involontaria, edició de Rodolfo Montuoro, Roma, Nottetempo, 2006, pp. I43-I44; citat parcialment amb petites diferències per Lodovica BraIdA, «L'autore, l'editore e il lettore nelle memorie di Valentino Bompiani», dins Valentino Bompiani, il percorso di un editore «artigiano", edició de Lodovica Braida, Milà, Sylvestre Bonnard, 2003, p. 67.

Cercles. Revista d'Història Cultural, 22 (2019), 111-134. ISSN: 1139-0158. ISSN-e: 1699-7468. DOI: 10.1344/cercles2019.22.1004. 
les d'amics seus: l'escriptor Massimo Bontempelli, el pintor Felice Casorati i el poeta Lionello Fiumi. El nom de Giardini, a banda de les cartelleres teatrals de l'any I9I2, es va fer conèixer a Catalunya a partir dels inicis dels anys vint, sobretot gràcies a La Revista, dirigida per López-Picó, que comptava amb molts colllaboradors (Plana i Rovira i Virgili, entre d'altres). Encara firmava com a «Cesarino Giardini». El 1922, a l'esmentada La Revista, ${ }^{24}$ Joan Malagarriga li publica la traducció al català d'alguns poemes. Un té un títol molt lullià («Desconhort»), amb un fortíssim tret autobiogràfic i amb un projecte de «fer coses» i viure una vida «útil». El poema conclou així:

Viure una vida inútil i migrada en excés enfront del món que no escatima pau ni beutat; i haver, després de mort, eix epitafi benaurat: "Aquí jau Cesarino Giardini. Visqué. No féu res més.»

L'any anterior, La Veu de Catalunya $a^{25}$ havia publicat un article sobre Alfons Maseras a Itàlia en què es feia un elogi de Giardini com a traductor de Maseras («poesies [...] bellament traduïdes a l'italià per En Cesarino Giardini»). Moltes altres revistes es van ocupar de Cesare Giardini i en van editar articles, relats i poemes als anys vint. Al final de la dècada (I929), la revista D'Ací i d'Allà publicà una de les dues fotos que queden del nostre actor-escriptor. ${ }^{26}$ No desconegut a Catalunya en el medi intel.lectual, però conegut sobretot a Itàlia. L’any 1923 comença a treballar (més ben dit, a col-laborar) a l'editorial Alpes, i això marca un veritable punt d'inflexió dins la seva activitat. Escrivint a Joan Estelrich entre els anys 1922 i 1923 fa servir paper amb capçaleres de revistes i de companyies teatrals. A partir de

24 XVI, I922, p. II8.

25 Edició del vespre del I6 de juny de i92I, p. II.

26 Vol. XVIII, núm. I35, p. 8I. 
I923 es regularitza l'ús del paper i de targetes postals amb la capçalera d' "Alpes Casa Editrice», on es quedarà, amb funcions molt importants, fins l'any I93I. Això ho sabem per una carta que Giardini escriu a Ramon d'Alòs-Moner el 29 de setembre de I93I:

Prima di tutto la mia uscita dalla "Alpes"; ormai da tre mesi non faccio più parte della Casa Editrice cui avevo dato tanto lavoro e tanta passione. In principio la cosa $\mathrm{mi}$ ha addolorato, ma ora mi sono già abituato all'idea d'indirizzare diversamente la mia vita. Poi mi sono buscato un esaurimento nervoso che mi ha obbligato a ritirarmi per un mese sui monti. $^{27}$

No sabem les raons d'aquest acomiadament. Alpes no anava gens bé des d'un punt de vista econòmic, tot i que la presidís el germà de Benito Mussolini, Arnaldo, que va morir el mateix I93I, i que estigués situada al costat del feixisme, amb tots els avantatges que això suposava. Giardini, segons consta en la documentació del fons Ciarlantini, era l'empleat més ben pagat, amb un sou lleugerament inferior al del mateix director de l'empresa, el diputat feixista Franco Ciarlantini. Malgrat aquesta proximitat, fins i tot física, amb importantíssims membres i prohoms de la jerarquia feixista, Giardini no pertanyia pas al Partit Nacional Feixista, tal com consta en un document de la Prefettura (Govern Civil) de Milà que he trobat a l'Archivio di Stato d'aquesta ciutat (el document es trobava dins una carpeta amb data 7 de febrer de 1938); es tracta d'una nota escrita a mà (adreçada al mateix prefetto, o governador civil) com si fos «confidencial», que diu: "[Cesare Giardini] È scrittore e traduttore da lingue straniere. Da tempo ha smesso di collaborare ai giornali. Soddisfacente / regolare. Non è iscritto al P.N.F. Gode buona reputazione». ${ }^{28}$

27 Fons Ramon d'Alòs-Moner i de Dou. Arxiu de l'Institut d'Estudis Catalans. 28 Archivio di Stato (Milà), Gab. Pref. II B. 7. 
A l'Arxiu Bompiani hi ha també una carta de Joaquín Arrarás en què elogia la traducció a l'italià feta per Giardini del seu llibre sobre Franco, que acabava de publicar Bompiani. Escriu Arrarás: «ya sabía de sus altísimos méritos como escritor y de su pasada labor como traductor de obras españolas [...] es usted el traductor ideal para una obra española». ${ }^{29}$ Giardini havia publicat fins al 1937 molt poques traduccions de l'espanyol i la traducció en plena Guerra Civil d'un llibre tan compromès amb el franquisme pot semblar sospitosa. No hi ha cap resposta de Giardini a la carta d'Arrarás. Giardini era un professional de la traducció (de moltes llengües, que coneixia més o menys bé) i feia les feines que li encomanaven. Aquest «no feixisme» de Giardini queda confirmat també a les seves cartes dels anys següents. En aquest sentit, no crec que l'acomiadament de l'editorial Alpes sigui una conseqüència més o menys directa de les lleis fascistissime dels anys 1925 i 1926 . La raó més important em sembla l'econòmica, tal com matisarem més endavant. Tot i així, hem de subratllar que si bé Giardini no va combregar amb el feixisme, tampoc va ser gaire crític amb els seus plantejaments, com sí que ho va ser el seu amic, i també editor, Piero Gobetti. Gobetti fou l'editor de l'Antologia di poeti catalani contemporanei I845-I925, llibre que té una història molt llarga que es remunta a cinc anys abans de la seva publicació: és una idea que va començar a perfilar-se entre els anys I92I i I922. Tractarem d'alguns aspectes d'aquesta història, però ara vull subratllar això: Giardini va escollir el molt jove editor de Torí (va morir als vint-i-quatre anys a París a consequència de la violència feixista) perquè no volia omplir el catàleg d'Alpes amb llibres seus (ja hi havia publicat l'any I924 la traducció italiana de La nacionalitat catalana, de Prat de la Riba, i l'any 1925, Il fascismo ita-

29 Arrarás a Giardini, 9 d'octubre de 1937. Archivio Rizzoli. Fondo Casa Editrice Valentino Bompiani (Milà). Area Editoriale. Serie «Corrispondenza con gli autori». Segnatura I42ACEB. 
liano, de Francesc Cambó, obra que altres editorials italianes han reeditat recentment dues vegades), i desitjava per a la seva antologia una editorial de qualitat i oberta a les literatures estrangeres. L'editorial del jove Gobetti reunia totes les condicions. La darrera carta de Giardini a Gobetti (26 de novembre de 1925) dona els detalls tècnics que havia de tenir l'Antologia, les seves (de Giardini) «manie di bibliofilo» $\mathrm{i}$ les condicions econòmiques. No hi ha cap referència a la situació política, encara que l'antifeixisme actiu de Gobetti era molt conegut a Torí i a tot arreu. Aquestes són les alllusions que en fa Giardini a Estelrich (però mai en parla directament amb Gobetti): «Ora le edizioni Gobetti - per ragioni politiche - han cambiato nome e si chiameranno Edizioni del Baretti [i amb aquest nom l'editorial publicarà l'Antologia de Giardini]» $;^{30}$ un mes després subratlla: "Come le ho già detto, per ottenere che l'amico Gobetti - morto in questi giorni lasciando la Casa Editrice a una società anonima che ha cambiato il nome delle edizioni - pubblicasse l'Antologia io ho rinunciato a ogni diritto d'autore», ${ }^{31}$ tot demanant a Estelrich una mena de compensació econòmica. Giardini a les seves cartes mai anomena «l'expansió catalana» que hi havia darrere les iniciatives d'Estelrich d'aquest caire. No vull aprofundir aquí en tot el llarg procés de la publicació de l'Antologia de Giardini. ${ }^{32}$ Només recordo que també Ravegnani havia manifestat la idea de fer una antologia de poetes catalans. ${ }^{33}$ Tots dos treballaven en temes contemporanis i

30 Giardini a Estelrich, 6 de febrer de 1926. Fons Joan Estelrich. Arxiu de la Biblioteca de Catalunya.

3I Giardini a Estelrich, I6 de març de 1926. Fons Joan Estelrich. Arxiu de la Biblioteca de Catalunya.

32 V. també Alessia Pedio «SCHedA» i Veronica Orazi, «Giardini e la cultura catalana", dins Cesare GIardini, Antologia di poeti catalani contemporanei I845-I925, Roma, Edizioni di Storia e Letteratura, 20I8, pp. 287-314.

33 Ravegnani a López-Picó, 26 d'abril de I921. Fons AHCB3-299/5D46 Josep M. López i Picó. Arxiu Històric de la Ciutat de Barcelona. 
molt semblants, però finalment Ravegnani publicà una antologia de relats catalans (1927) ${ }^{34}$ i Giardini, la seva antologia poètica (I926). Em sembla més interessant ara conèixer la reacció dels intel.lectuals italians a la publicació d'aquesta obra. Giardini podia comptar amb molts bons amics i contactes als principals diaris italians. I, efectivament, l'Antologia va tenir moltes ressenyes. Només parlarem de la — potser- més important, i per dues raons: perquè es va publicar al Corriere della Sera i perquè la va escriure un gran periodista, Orio Vergani, que torna a subratllar el tema polític més que l'aspecte literari, el qual, per cert, coneix molt poc (i es nota):

[...] anche se fra le righe compiute delle critiche e quelle incompiute della poesia si riconosce il fremito di un problema politico tanto all'animo dei poeti quanto alla cultura degli accademici della nuova lingua: per cui, mentre i poeti cantano i politici si danno la mano. [...] Se per raggiungere [un'assoluta aderenza tra concezione ed espressione] i poeti catalani rinunciano intanto a essere letti $[. .$.$] non si può non riconoscere$ loro una buona dose di eroismo e una notevole capacità di sacrificio [...]. Il compilatore dell'antologia ci parla spesso di grandi poeti, ma questi grandi non ci danno troppo spesso la grande poesia [...]. Questa giovane poesia senza passato - cent'anni sono ancora l'infanzia per le muse di un popolo [evidentment Vergani ignora la història literària catalana] ci pare [...] notevole perché si sforza di costruire oggi quello che domani sarà il passato; gli strati della tradizione... [...] Anche se non vasta messe, è un manipolo di spighe d'oro. ${ }^{35}$

Tot i l'avaluació positiva, com a mínim d'una petita part dels poemes, el tema és l'heroisme i el sacrifici dels qui, per una raó més aviat política, renuncien a tenir lectors fent servir una llengua que prescindeix de traduir al castellà el pensament català, tal com ho diu

34 Antologia di novelle catalane, Milà, Firme Nuove, 1927, 245 p.

35 Corriere della Sera, 27 de juny de I926, núm. de pàgina il.legible. 
Vergani. L'Antologia va aconseguir, com he dit, moltíssimes ressenyes. En tenim constància gràcies als comentaris fets per Giardini a Estelrich sobre això. S'ha insinuat també que la selecció proposada per Giardini seria una selecció suggerida en realitat per Carles Riba. $\mathrm{Ni}$ les cartes a Riba ni les cartes a Estelrich ho demostren. Al contrari, Giardini es queixa d'aquesta «acusació» (que ve de Tomàs Garcés). Escriu Giardini a Carles Riba:

So che la mia "antologia" non è piaciuta a tutti costì. Mi si rimprovera di aver lasciato da parte alcuni poeti del gruppo romantico, che, francamente, non mi interessavano. Un amico di costì mi ha anzi scritto una lettera quasi violenta, facendomi credere che egli pensava io fossi stato indirizzato male nella mia scelta da persone interessate di costì. La cosa è assolutamente infondata poichè, bella o brutta che sia la mia antologia l'ho fatta io senza chiedere consigli a chicchessia. Mi piacerebbe sapere il parere in proposito di Tomàs Garcés, poichè la persona che mi ha scritto la lettera in questione, dice che ha parlato con Garcés e questi gli ha dato ragione. ${ }^{36}$

Giardini tenia llavors un coneixement prou ampli de la poesia catalana (des de feia com a mínim cinc anys llegia poesia catalana), que li podia permetre fer-ne una selecció; tot i això, és veritat que li van arribar alguns «suggeriments» de Riba i també d'Estelrich, tal com el mateix Giardini reconeix en una carta a Piero Gobetti: "[Riba i Estelrich] mi hanno scritto che dovrebbe figurare nella collezione anche Jacinto Verdaguer [...] ch'è il capostipite della poesia catalana. A tal uopo ho tradotto tre poesie che andranno innanzi a tutte». ${ }^{37}$ Efectivament, l'Antologia comença amb tres llargs

36 Giardini a Carles Riba, is de juliol de 1926. Fons Riba-Arderiu ANCI-26. Arxiu Nacional de Catalunya.

37 Giardini a Gobetti, 3 d'octubre de 1925. Archivio Fondazione Piero e Ada Gobetti (Torí), carteggio Giardini-Gobetti.

Cercles. Revista d'Historia Cultural, 22 (2019), 111-134. ISSN: 1139-0158. ISSN-e: 1699-7468. DOI: 10.1344/cercles2019.22.1004. 
poemes de Verdaguer evidentment proposats per Riba o Estelrich. La publicació del llibre de Giardini va tenir ressò també a Catalunya perquè l'antologia representava un reconeixement internacional del nivell assolit per la poesia catalana. Es parlà també molt, i a moltes cartes, de l'antologia de poesia catalana d'Albert R. Schneeberger que s'havia publicat pocs anys abans (1922) i que Giardini havia criticat en moltes circumstàncies. En aquest sentit, la selecció de Giardini (molt diferent, per cert) també s’insereix dins el programa d' «expansió catalana», com les obres anteriorment publicades (La nazionalità catalana, de Prat de la Riba, ${ }^{38}$ i Il fascismo italiano, de Cambós9). Tal com ho diu clarament Giardini l'any 1924: «Riprenderò il mio lavoro di propaganda catalana. Ella sa con quanto amore lavoro». ${ }^{40}$ Com ja hem assenyalat, l'Antologia dei poeti catalani contemporanei s'ha tornat a editar el 2018 en edició facsímil amb un estudi de Veronica Orazi i Alessia Pedio sobre "Giardini i la cultura catalana» i una "fitxa» d'Alessia Pedio sobre la relació entre Giardini i Gobetti, dins una collecció de l'Edizioni di Storia e Letteratura que està reeditant totes les obres publicades per l'editorial de Gobetti.

Les esmentades La nazionalità catalana i Il fascismo italiano han estat molt ben estudiades en la seva relació amb Giardini per Giovanni C. Cattini (2009) ${ }^{41}$ i les tractaré, doncs, només de passada, alludint al paper de Franco Ciarlantini, director de la «Biblioteca di Cultura Politica», dins la qual es van editar tots dos llibres. Em va sobtar que al fons Ciarlantini, de la Fondazione Ugo Spirito e Renzo

38 Enric Prat de la Riba, La nazionalità catalana, introducció i traducció de Cesare Giardini, Milà, Alpes, I924, XXVI + 126 p.

39 Francesc Самвó, Il fascismo italiano, traducció de G.C. i prefaci de Franco Ciarlantini, Milà, Alpes, I925.

40 Giardini a Estelrich, I4 de gener de I924. Fons Joan Estelrich. Arxiu de la Biblioteca de Catalunya.

4I Vegeu la nota 6.

Cercles. Revista d'História Cultural, 22 (2019), 111-134.

ISSN: 1139-0158. ISSN-e: 1699-7468. DOI: 10.1344/cercles2019.22.1004. 
De Felice de Roma, que té una quantitat molt notable de documents sobre Alpes - la més important perquè de l'arxiu d'aquesta editorial n'ha quedat ben poc- només hi hagi una carta de Giardini a Ciarlantini sobre un llibre que els havia recomanat Italo Balbo i que a Giardini no li acabava de fer el pes. Res sobre el llibre de Cambó i res tampoc sobre Prat de la Riba. Ara bé, s'ha de dir que encara no s'ha fet un inventari complet del fons, però m'he mirat totes les carpetes que l'integren. L'inventari puntual podria descobrir coses que no vaig poder veure entre tants papers i documents més o menys desordenats. Estic, però, convençut que els dos llibres esmentats els va suggerir a l'editorial el mateix Giardini i que només havien de satisfer les condicions polítiques (clarament fonamentals) de la collecció. Això es desprèn d'una carta a Estelrich en què Giardini escriu: «Caro amico, mandi pure il manoscritto del volume del sig. Cambò: lo esaminerò e, se non contrasta con le direttive poltiche della collezione diretta dall'on. Ciarlantini, lo pubblicheremo presso la Casa editrice 'Alpes'». ${ }^{42}$ Però el llibre, evidentment acceptat, tenia i té una característica que no tenien els altres llibres editats per Giardini, que sempre havia firmat les seves traduccions. En aquest cas concret, no ho va fer. La portada diu textualment: «Francesco Cambò / Il Fascismo italiano / traduzione di G.C. / Prefazione di F. Ciarlantini». Per què Giardini no va firmar aquesta traducció com sempre havia fet amb les altres? Doncs la resposta la tenim en una carta a Estelrich. Anota Giardini: «Ho dovuto rifare completamente la traduzione chè quella inviatami da lei era inservibile. La traduzione ora è molto buona», ${ }^{43} \mathrm{i}$ afegeix també que la "prefazione» de Ciarlantini es deu a un esbós escrit per Estelrich: «Potrei forse collocare un ampio articolo

42 Giardini a Estelrich, I2 de novembre de I924. Fons Joan Estelrich. Arxiu de la Biblioteca de Catalunya.

43 Giardini a Estelrich, 23 d'abril de 1924. Fons Joan Estelrich. Arxiu de la Biblioteca de Catalunya. 
sulla Catalogna politica nella 'Rivoluzione liberale' del mio amico Gobetti: bisognerebbe che lei mi facesse avere una traccia, come ha fatto per la prefazione al Cambò». ${ }^{44}$ Sembla, doncs, que les pàgines del pròleg, firmades per Ciarlantini, contenen moltes idees i informació d'Estelrich i també de Giardini: sobretot les pàgines sobre Catalunya i l'elogi de l'obra i la figura de Cambó. Però hi ha parts, a partir de la pàgina XI fins al final, que semblen més genuïnes i escrites pel director de la "Biblioteca di Cultura Politica», en què Ciarlantini precisa l'abast i el rigor del credo feixista contra possibles crítiques i dubtes sorgits arran de la lectura del llibre de Cambó. Algunes conclusions del volum tenen relació directa amb Espanya i no pas amb Itàlia:

Il libro ha per gli italiani un interesse vivo che appare al di sopra d'ogni voluto o sospettato significato ermetico: v'è studiato, analizzato, volta a volta, esaltato e criticato, un movimento politico che ha mutato dall'oggi al domani le sorti d'Italia e del quale anche i più malevoli debbono riconoscere l'importanza e la trascendenza: il resto non conta; il resto, se mai, può riguardare gli spagnoli, non noi. ${ }^{45}$

Malgrat algunes crítiques, Cambó, com ha escrit Cattini, elogia l'antiparlamentarisme feixista i molts altres aspectes. En conclusió:

Io pubblico il libro perchè lo trovo sano e perchè predica il ristabilimento di quella gerarchia tra i vari poteri dello Stato e di quella benintesa autorità del potere esecutivo su quello consultivo che sono tra $\mathrm{i}$ maggiori postulati del Fascismo. Ma lo pubblico soprattutto perchè nelle belle pagine del Cambò si sente palpitare un grande amore per questa nostra Italia, fattiva e ricca di retaggi greci e romani come la sua Catalogna. ${ }^{46}$

44 Ibidem.

45 Francesc Самвó, op.cit., p. XI.

46 Ibidem, p. Xv.

Cercles. Revista d'História Cultural, 22 (2019), 111-134.

ISSN: 1139-0158. ISSN-e: 1699-7468. DOI: 10.1344/cercles2019.22.1004. 
És evident que escollir publicar el llibre de Cambó no va ser facil, ni es va fer, potser, sense comentaris de part d'alguns sectors del feixisme més intransigent representats dins d'Alpes. La seva gestació va ser complicada i la traducció, revisada de cap a peus per Giardini, però en principi feta per altres i no pas per ell, com hem vist. Les inicials de Giardini, en lloc del seu nom complet, signifiquen no tan sols diferents responsabilitats editorials, sinó el fet de marcar distàncies, potser també ideològiques.

Aquesta actitud tèbia envers el feixisme, juntament amb la crisi econòmica de l'empresa, van determinar potser el seu allunyament el I93I de la funció de consulente letterario de l'editorial. De fet, Giardini era més que això, $i$ es desprèn de les moltes cartes que escrivia a tots els autors publicats per Alpes. Als anys trenta i quaranta (i malgrat la guerra), Giardini desenvolupà una gran activitat, com a escriptor i traductor, per a les més importants editorials italianes. En aquest sentit, es pot llegir l'estudi (tot i que parcial) de Davide Fumagalli sobre Giardini durant el període d'entreguerres. ${ }^{47}$ Però mai va oblidar «els seus autors catalans» (des dels clàssics, com ara Llull i Muntaner, fins als poetes contemporanis, que ja hem vist). Àdhuc durant el llarg silenci de la dictadura franquista, va proposar a moltes editorials italianes les seves traduccions de literatura catalana (a vegades, amb èxit). La seva relació amb la cultura catalana començà llavors a assolir una dimensió mítica i, amb els editors que tractava, gairebé obsessiva. Poquíssimes són les cartes amb els autors catalans després de la Guerra Civil. I per raons ben evidents. La història i la literatura, sobretot de l'àmbit francès, passaran a ser fonamentals en la seva feina. Treballarà per a moltes editorials, com ja hem dit, però també per a la televisió italiana que acabava de néixer. Gramsci va

47 «Il lavoro editoriale di Cesare Giardini tra le due guerre», dins L'Officina dei Libri, núm. 2, edició d'E. Barbieri, L. Braida i A. Cadioli, 20II, pp. IOI-I34. 
incloure Giardini dins la categoria de la «literatura popular», ${ }^{48}$ categoria internacional amb molts pocs representants a Itàlia, i la televisió va ser la sortida natural d'un escriptor que no volia ser "popular», però que va acabar sent-ho.

48 «L'ultimo e più recente tipo di libro popolare è la vita romanzata, che in ogni modo rappresenta un tentativo inconsapevole di soddisfare le esigenze culturali di alcuni strati popolari più smaliziati culturalmente [...]. Anche questa letteratura non ha in Italia molti rappresentanti (Mazzucchelli, Cesare Giardini ecc.) [...] Essi scelgono i loro argomenti fuori d'Italia (Mazzucchelli e Giardini in Francia [...]), per adattarsi al gusto popolare italiano che si è formato sui romanzi storici specialmente francesi» (Antonio GrAMSCI, Letteratura e vita nazionale, Torí, Einaudi, I954, Pp. III-II2).

(c) (1)

Copyright $(\odot$ 20I9. Aquesta obra està subjecta a una llicència de Creative Commons mitjançant la qual qualsevol explotació n'haurà de reconèixer els autors, citats a la referència que apareix a l'inici del document.

Cercles. Revista d'Historia Cultural, 22 (2019), 111-134.

ISSN: 1139-0158. ISSN-e: 1699-7468. DOI: 10.1344/cercles2019.22.1004. 